\title{
Finding Our Way Home (at School): A Study Of Students' Experiences of Bringing Their Home Culture into the Classroom
}

\author{
Christina Parker \\ OISE, University of Toronto
}

\begin{abstract}
This study is concerned with how children conceptualize their cultural identity, and how this conceptualization may impact their learning and socialization at school. It explores how students' self-concept and perception of others can develop through investigations of their own cultural and ethnic backgrounds while situating their familial history within the multicultural city in which they live. Participants in this study, a class of 29 Grade 4 students in the Greater Toronto Area, conducted online research, interviewed relatives, and created family trees to learn about their cultural heritage and gain a better understanding of themselves and their family's history. The following paper provides an in-depth case study of three of these participants. Insights into their experiences and learning as they engaged in this process of cultural investigation are explored and implications for policy and practice are identified.
\end{abstract}

\section{Finding Our Way Home (at School)}

This paper draws on a larger research study that investigated how Grade 4 students conceptualize their cultural identity. For the purposes of this paper, I focus on the experiences and challenges of three of these students as they explored their cultural identity at school. Through the use of case studies, insights into the students' lives are examined, as we learn about Peter's experience with being a new Canadian, John's complex connection to his homeland, and Vanesh's second-generation immigrant conceptualizations. Through this introspective study it became apparent that students not only want to find ways to bridge the home and school divide, but that they already have. They do this every day, when they have informal conversations outside of school, asking each other, "Where are you from?," "What religion are you?," "Where were your parents born?," "What languages do you speak?" Or perhaps, "I saw you at temple on Sunday, are you a Hindu?," or "Do you celebrate Eid ul-Fitr?" We are naïve if we believe that children do not converse in this manner. The problem is that these conversations usually take place beyond the classroom door. In this 
research I question why it is that conversations about what one's family does at home are so frequently dropped when children arrive at school. Perhaps it happens because some of us want to continue reading the story about the white mother and father who are sitting down with their daughter and son to have Christmas dinner. One cannot but wonder about the effect of such a story in a classroom where 23 ethnicities are represented among 29 students; where 14 are second-generation immigrants and are children of colour; where others live in single-parent households; and where and one lives in a foster home. In this paper, I outline stories - children's stories - of how they experienced a project that explicitly asked them to bring their home culture into the classroom. I then elaborate on how these curricular experiences influenced students' understanding and perceptions of their cultural identity.

\section{Conforming Rather Than Exploring}

As students strive to be fully accepted into mainstream society, they try to dissociate themselves from their families by purposely not speaking their first language or connecting with their cultural heritage. Urrieta and Quach (2000) pointed out the importance of valuing ethnic identities, having found that ethnic minority students attach negative connotations to their ethnicity in an attempt to fit in. It is important, therefore, to facilitate ethnic minority students' acculturation by encouraging them to identify positively with their cultural and ancestral history, rather than adopting a "fake" identity simply to fit in with what is considered the norm. Lee and Hebert (2006) confirmed Urrieta and Quach's argument, noting that the immigrant students they researched had strong attachments to their ethnic culture and identity because at their school their ethnocultural identity was recognized and they received group support during their settlement period, allowing them to identify both with the larger political community and their own.

Students need to be taught to feel positively about both their Canadian identity and their cultural heritage. Kymlicka (2003) suggested that identifying with being Canadian is just as important as identifying with one's sub-group identity. Therefore, while many policies promote and call for a greater inclusion of diversity and multiculturalism, citizenship education should not be replaced with learning solely about other cultures, but rather should nourish the bicultural identities of our students (Darder, 1991). Portes and Rumbaut's (2001) coined the term selective acculturation to describe the process of how second-generation immigrant students navigate through the many identities they carry with them to school, choosing what to retain and what to let go of. Cummins (2007a) pointed out that selective acculturation "slows down the cultural shift and supports retention of the parents' home language and at least partial adherence to family cultural norms" (p. 9). This type of veiled identity is one that some new immigrants choose. The idea that all immigrants proudly maintain their culture could easily be skewed, as in many cases people who move to Canada try ceaselessly to remove all markers of their culture, attempting to shed it in every way possible so as to produce a new culture, one that amounts to a type of "Canadian identity." As a result, many students may not want to speak about their cultural heritage, or to be identified as "other," and who may really want to remodel their culture in every way to conform to their new society. 
Bissoondath (1998) pointed out that exoticizing multiculturalism policies further marginalizes immigrants. In describing his own migration experience, he questioned why, after having lived so long in Canada and having become "Canadian," his Canadian-born daughter would be referred to as "West Indian." While he hoped that people would no longer ask others about their ethnic origins in years to come, children still must be equipped to respond to such questions about their cultural and ethnic backgrounds, because, ultimately, it is part of who they are. For that reason it is even more important for children who are growing up within families that dismiss their cultural background to be even more prepared to speak about their cultural and ancestral heritage-their food, language, people, and history. Schools are places that provide unique spaces for this kind of cultural exploration. Delpit (1995) argued that educators must connect with the rich home lives of their students and understand the families and communities to which their students belong, in order to appreciate the experience of people from other cultural backgrounds. She called for a revamping of teacher education programs, to prepare teachers to focus on culturally relevant pedagogy in their classrooms. For Merryfield (2004), elementary teachers, in particular, need to be equipped to engage students in substantive cultural learning. She argued that educators "have a primary responsibility for opening students' eyes to the world and its peoples" (p. 270). For Ramsey (2004), the only way to overcome the complexity of addressing multicultural issues in the classroom is to build strong relationships between parents, homes, and schools.

\section{Connecting the Experience of Knowers and Knowledge They Create}

Legislation and policies in Canada recognize the growing multicultural and ethnic composition of the country. Minority and cultural rights are recognized within the Canadian Charter of Rights and Freedoms (1982) and the Canadian Multiculturalism Act (1985). For its part, the Toronto District School Board has a comprehensive equity policy for all its schools that addresses five areas: (a) antiracism and ethnocultural equity; (b) antisexism and gender equity; (c) antihomophobia, sexual orientation, and equity; (d) anticlassism and socioeconomic equity; and (e) equity for persons with disabilities.

However, despite the many multicultural policies in Canada, implementation of them is difficult to measure. As a result, some argue that policies concerning multiculturalism are purely rhetorical (Chan 2007; Kymlicka, 2003; Peck, Sears, $\&$ Donaldson, 2008). Chan found that implementing policies meant to bring students' home culture into the school was not always positively received at school, and that a gap existed between the policies and the students' experience (p. 190). Chan researched how students experienced a culturally sensitive curriculum in a diverse community in Toronto and found that when "students come to school they bring their home cultures, developed through interaction with family and community members" (p. 178). In the end, Chan noted, simply knowing the country a student is from is insufficient to adequately plan a curriculum that is culturally sensitive; it is important to know more in-depth narratives about the student's cultural history in order to acknowledge it adequately.

Dudley-Marling (1997) attempted to engage with his students' cultural narratives while teaching a diverse group of Grade 3 students in Toronto. He 
decided to read folktales from the cultural backgrounds of all the students in the class. However, Dudley-Marling mistakenly assumed one of his students was from Pakistan when in fact he was from Afghanistan and had spent a year in a Pakistani refugee camp. When he read a Pakistani folktale, he asked this student to expand on it (thinking the student would be happy to speak about his cultural background), only to hear the student say, "I'm not from Pakistan." DudleyMarling's experience showed that students may be sensitive to discussions that highlight their perceived ethnicity and experiences in their homeland and subsequently may not want to identify with certain aspects of their cultural and migration history.

Clearly it is important that students be given the freedom to choose to tell their own stories. When students are asked what they want to talk about, they can then participate in constructing their own cultural identity and not have their teacher decide it for them. As Banks (1997) argued, it is important for students to "make connections between the autobiographical experiences of knowers and the knowledge they create" (p. 80).

There is an evident need to incorporate a multicultural and culturally sensitive curriculum in today's classrooms to meet the needs of an increasingly multicultural society (Banks, 1997). Hyun (2007) noted that from a very young age, children are oriented to multiple cultures of race and ethnicity, and aware of a "socioculturally conditioned world filled with many different conditions of cultural differences" (p. 262). As more children are raised in what Hyun referred to as a culturally complex world, teachers must include culturally appropriate and culturally responsive curricula in their pedagogy. Ultimately, Dudley-Marling (1997) acknowledged, “people's cultural and religious identities are complicated by factors like race, class, language, socioeconomic status, gender, and so on" (p. 130). He realized that his "attempts to match literature to students' ethnic backgrounds were based on a homogeneous sense of culture that ignored the complicated ways people construct their cultural identities" (p. 130). When students are confronted with stories to which they essentially have no connection, they are left with little choice about how they are seen and represented to their class. Furthermore, the way in which one student's family lived in their home country might not be representative of others in that country. Therefore, it is important for schools to assist students to develop strong identities with their cultural communities. Equally, curricula must promote global and cultural interconnectedness within our local communities, to "help students develop the knowledge, attitudes, and skills needed to function within various cultures in their own society" (Banks, 2006, p. 25).

\section{Role of the Researcher and Methodology}

My enthusiasm for this research was fuelled by my own experience of growing up in the Greater Toronto Area (GTA) as a first-generation Canadian (a secondgeneration immigrant). For this study, I helped students explore their cultural heritage by sharing with them techniques that I had used to explore my own cultural background, including examining my cultural identity as a child. In designing and implementing this research project, my goal was to draw students' attention to their culture and family heritage so that they could learn more about themselves and their cultural backgrounds. 
I worked with the classroom teacher to implement a cultural heritage unit in a diverse Toronto-area class of 29 Grade 4 students. The unit included four stages: (a) an online student research project, (b) creation of a family tree, (c) interview of a relative, and (d) a cultural fair where students presented their research. As the students worked on this project, which required that they examine their cultural selves, I undertook detailed observations through field notes. I also collected reflective journal entries that the students wrote over the 4-week period, which documented how their perceptions, feelings, and learning evolved as they participated in the unit. Qualitative data included students' online research, family trees, grandparent interviews, the cultural fair, and the students' reflective journal entries. Selected themes were found within the qualitative data, which were analyzed using a grounded theory approach (Glaser \& Strauss, 1967) in which observational data are permitted to influence the coding and evaluation.

In this paper, I draw on the qualitative data gleaned from the reflective journal entries of three students. Through exploration of the curricular experiences of these three students, the importance of listening to students' voices when implementing curriculum is revealed. I will discuss emergent themes found in students' journal entries, which will be illustrated using a case study approach. Students' experiences become real through telling these stories: "My Family Goes Back Six Generations Canadian," "My Grandparents Only Speak Chinese," and "I Was Born in Canada But That Still Makes Me Sri Lankan."

\section{Findings}

Canadian through and through: "My family goes back six generations Canadian"

As the students prepared to conduct online research by looking up the country or countries they believed represented their ancestral history, John was the only one that decided to put "Canada" into the Google search box. He was the only student in the class who did not identify with any country other than Canada. I engaged in many discussions with John, trying to explore elements of his ancestral history. I asked: "Has anyone ever told you where your great-grandparents or their parents came from?" He continued to look at the computer screen and sternly said: "My family goes back six generations Canadian." I continued to press: "Do you know where the generation before that came from?" John smiled at the computer screen, looked up at me and said, "Do you know that I have lots of famous people in my family?" John changed the subject; he didn't want to talk about his cultural history because according to him, he didn't have one.

And so John began his research on Canada and noted many facts about Canada's history in his first journal entry such as John A. Macdonald, Confederation in 1867, and the wealth of rocks and minerals in Canada. His assignment that week was to create a family tree. Students were also prepped to conduct a grandparent interview in the coming weeks. The next day John's mother visited the classroom after school and asked to speak with the classroom teacher. The teacher, Mr. Watts, and John's mother stepped out of the classroom while I, the educational researcher in the classroom, looked on. When Mr. Watts returned I asked him if there was something I should be concerned about. 'John's 
mother thinks that he is receiving too much homework and is not convinced that he should be having to spend all this time researching his family." I responded, "But she gave her consent to allow John to participate in the curriculum unit and research study." Mr. Watts said he had explained that to her, and had told her that the Grade 4 curriculum document contained the expectation that students would be asked to conduct interviews of some sort. I considered the possibility that John's mother's reluctance for him to participate in this unit could have stemmed from her never having asked herself that special question, "Who am I? Where do I come from?" However, John continued his research and in his second entry he wrote: "I want to learn more about who started my family. I also want to know about anyone famous in my family as well as who my great, great, great, great, great, great granddad is."

John got together with his grandfather, and created a beautiful and detailed family tree. He discovered his family's ancestry through interviewing his grandfather, and reflected: "I learned that my family started in Britain about 2000 years ago and that there were so many people in my family." The project finally caught John's attention. He wasn't "pure" Canadian after all. John announced, "I want to know more about my family's past because history is very interesting. I learned that my Nana wore bobby socks and listened to rock and roll. Also that dads worked and mothers stayed home." John became a history addict. What was even more interesting about John was that as he began to learn about his grandfather's and grandmother's lives and their experiences living in Canada, as well as his ancestors' experiences of migration to Canada, John also took interest in his best friend Jacob's Lebanese heritage. He wrote in his journal that:

I think it is important to learn about other cultures because they can be very cool and their cultures may have interesting languages. I learned from my classmate that you read Lebanese right to left and that there were tons of wars in Lebanon. The most interesting thing I learned was that Lebanon had the biggest stone structure on earth.

John's experience researching his family was powerful. His learning curve and interest was intense. What had at first appeared to be stubbornness turned into what I hope will be a lifelong learning journey. He wrote his final journal entry in the form of a poem:

Cultures
Using information
Letting loose info
Today
Unknown things
Really cool
A fun thing
Letting people know things
Foreign countries
A nice project
I had fun
Reading

John's experience revealed that while many people have been here in Canada for 
many generations, there still are possibilities in exploring those histories. Through this kind of exploration, students begin to understand and accept those around them who come from different cultures. John's experience also demonstrated that despite the length of time one's family may have spent in Canada, one can still explore - and, as in this case, find great interest in connecting with one's cultural and ethnic origins through many generations of history.

\section{New immigrant barriers: "My grandparents only speak Chinese"}

Peter was the only student in the class who was not born in Canada. He and his family were new immigrants from China. He appeared to have little parental guidance and struggled to describe his cultural heritage in any depth. While Peter's experience illustrated some of the challenges children who are new immigrants face, his case also showed that parental support and language acquisition are key factors in students' integration. What may have appeared to be Peter's lack of interest in the project could actually have been his frustration with not being able to communicate his ideas and familial knowledge in English. When I explained the components of the assignments to students, Peter raised his hand to explain that he could not do the assignments because his grandparents live in China and they only spoke Chinese. The fact that Peter's grandparents spoke Chinese made Peter nervous. I asked him, "Do you speak Chinese?" "Not very well," he replied. When I told Peter that he could instead interview his mother, father, or any other relative, such as an aunt or uncle, he continued to protest, saying that his parents were always at work. In the end, Peter produced a Bristol board display about China, albeit with limited detail. His journal entries showed some improvement during the course of the unit; however, each was only one or two sentences long.

Overall, Peter participated in class discussions and during the last week of the unit, he bravely raised his hand to tell the class one of his experiences about going to school in China. The class had read aloud a book entitled The Name Jar by Yansook Choi, about a girl named Unhei who is embarrassed by her Korean name when she first goes to school in America, because her classmates could not pronounce it. Peter shared his experience of moving back to China for a few years after his family first came to Canada. In China, he continued to use "Peter" rather than his Chinese name; many of his classmates were unable to pronounce his Canadian name and made fun of him. After Peter told the class this story, his peers enquired about his Chinese name and Peter proudly shared it with them. Despite the limitations Peter experienced in terms of access to familial knowledge and English language skills, he did in the end become more confident in sharing stories from his homeland with the class.

\section{Second-generation immigrant identity: "I was born in Canada but that still makes me Sri Lankan"}

Vanesh was disengaged at school. While the rest of the class sat in groups, he sat by himself at the front of the classroom facing the blackboard. From the moment I met him, I wondered what effect this project would have on him. "What do you know about your family's history?" I asked. "My family is from Sri Lanka," he 
replied, "but I want to know more." After conducting online research on Sri Lanka and going home and speaking to his family, Vanesh reflected in his first journal entry:

I learned that the special clothes that my culture wears for girls is the sari. And our god is the Buddha. The special food we eat is rice. In our country we have a big mountain shaped like a lion we call Ceylon. And our country grows tea leaves and make tea in a factory that my relative works in.

Vanesh became involved in this project; he felt proud. Vanesh went to the library and took out a book about flags. I saw him at his desk flipping through the pages frantically looking for the flag of Sri Lanka. I stood by and watched as he spoke aloud to himself, "The flag of Sri Lanka has three colours." "What do you think the colours represent," I intervened. "I don't know," he replied, "but maybe it says here," as he pointed to the page. He read and then proudly announced, "Each colour on the flag stands for a background." "A background?" I asked. "Yes, one colour stands for Hindus, one for Buddhists, and the other for Muslims. My background is Buddhism." "You mean your religion?" I pressed. "Yes my family's religion is Buddhism and we speak Singhalese." Vanesh's enthusiasm and connection to Sri Lanka was not unusual. Many students who are second-generation immigrants value their Canadian nationality, but maintain a strong connection with their ethnic selves. Like John, Vanesh chose to write a poem during a journal entry:

My family was born in Sri Lanka but I was born in Canada
But that still makes me Sri Lankan
Because my family was born there
My background is Sri Lankan even if
I live in Canada
I live in a house
In Sri Lanka and Canada
I am a Canadian citizen
My family is great
My family is very nice too!
I like to live in Canada because
There is much more space
Here and it is very big.

Vanesh's connection to his ethnic self was consistent with what Lee and Hebert (2006) found when immigrant students connected with their ethnic heritage and showed that they understood multiculturalism to the extent that they were able to recognize ethnic identities associated with their Charter rights (p. 497). Vanesh's positive experience with this unit stemmed from his advantage in having access to his grandparents, and his privilege in being fluent in the language his grandparents spoke, Singhalese. This was a fortunate connection because many young children in Canada lose much of their first language quickly on entering the Canadian school system (Cummins, 2001; Wong, 1991). Vanesh's fortunate position allowed him to communicate with his grandparents who, in turn, were more than happy to tell him stories about his history. This development of 
intergenerational understanding was exhibited by Vanesh as he proudly noted in his fourth journal entry: "I learned from my grandparents our God is the Buddha. The temperature there is very hot. It is hot there because the equator is close to the island. It is located in the Indian Ocean and below India." In this same entry Vanesh introduced his best friend George and, he says, "[George] was born in Canada. [George's] background is Greek. He went there a month or so ago and came back." Vanesh found a similarity between himself and George. They were both born in Canada, but their parents came from another country. This realization allowed for even greater connections between Vanesh and George as they shared stories about their cultural histories and began a process of identity formation together.

By the end of the unit Vanesh's desk moved away from being the only one facing the blackboard at the front of the class to being merged within a group with his peers. He was on task, he was learning, and he was enjoying it. In Vanesh's final journal entry he reflected:

We had our cultural fair on Wednesday. It was very fun there. The
[other] grades came to interview us. Then they went and I interviewed a
lot of people. I learned about lots of countries. I got two recipes printed
on a piece of paper. The things about our backgrounds are on our
Bristol boards. We had a lot of fun for 4 weeks. Today is the last day
we write about our backgrounds. It was very very fun to learn about
other peoples' background.

Vanesh became engaged in the classroom because the content reflected something that he wanted to talk about. It reflected his "home culture" and he was able to "bring it to school." His experience points to the ways children who are second-generation immigrants have of finding a balance between their new Canadian identity and the cultural identity they carry from their parents.

\section{Access and Barriers}

Language barriers and the complexity of defining one's cultural identity, as shown in Peter's experience, are among the challenges faced when implementing a cultural heritage unit in the classroom. Another challenge is that not every student's cultural heritage can be easily defined. Some students chose to research two countries because they were of mixed ancestry; others in the same situation decided to research one or the other. Yet another of the students who participated in the unit lived in a foster home; he was given the option of researching his foster family's heritage, or of connecting with his grandparents whom he visited on weekends. In sum, it was a unique and personal learning experience for all; and it was the students who made these delicate choices for themselves.

Students who are new immigrants may not have the necessary parental and familial guidance that is required for this cultural heritage unit, often because many new immigrants experience poverty when they first arrive in Canada which may leave parents with little time to provide educational assistance (Kazemipur \& Halli, 2001; Picot \& Hou, 2003). Peter's case provided insights into some of the challenges children of new immigrants face, including language barriers and finding time because (according to him) they were always at work. Peter's story 
is reminiscent of one told by $\mathrm{Xu}$, Connelly, He, and Phillion (2007). They described the experience of Yang-Yang, who suffered from being lumped in with others of his ethnicity because of preconceptualized ideals many people hold regarding Chinese immigrants. When such ideas or standards take root, all Chinese immigrants become the model minority, and a hidden minority of Chinese students is created who are struggling academically while, often, their families are also struggling financially (Xu et al., p. 413).

The insights gleaned from implementing this unit raised questions about how such cultural heritage projects can be adjusted so that all students are included equitably. Not all students' cultural heritage is easily defined, and this may put some students in a difficult position. In addition, the unit required students to look into their ancestral countries, but the complexities of ethnicity and geopolitical boundaries could also pose problems for some students. For example, as we saw with one of Dudley-Marling's (1997) students who arrived from Pakistan, where he may have lived most of his life, but his familial roots were in Afghanistan. Similarly, if a student identified as being Kurdish, it could pose a challenge were he to Google his homeland's geopolitical boundaries. The students who participated in this study were all able to locate a country that represented their ancestral history (as they chose to perceive it, whether accurately so or not), and they were all able to locate information on various websites about the country or countries they chose.

\section{Welcoming Opportunities to Bridge Home-School Cultural Divides}

This project provided students with the opportunity to research a country that was personally significant to them. Their homework required that they speak to their family to gain insights into their ancestry. Students brought their information back to school and shared it with their classmates. As a result, it was clear that the connections between home and school were strengthened. Students showed keen interest in the project and in sharing with their friends at school what their family valued and did at home. Hearing such responses as "I liked the cultural unit very much because I got to show everybody what my family did" was stimulating and encouraging for educators and students alike. The excitement generated by students as they brought their home cultures into the classroom showed how important it was for students to be safe and comfortable about learning and teaching others about their home culture at school. Overall, students' development of intergenerational understanding was evident in their final journal entries. The interview with a grandparent was an important component of the cultural heritage unit, and provided students with an in-depth understanding of their families' histories.

Through studying these students' experiences I found that students welcomed the opportunity to bring their home culture into the school, and that they want more opportunities to do so. While this research included a whole unit focusing solely on students' cultural heritage, it is not necessary to undertake a special unit to show children the importance of nurturing and accepting their cultural heritage and those of others. Simple teaching strategies could be incorporated into or merged with many other subjects, such as geography, language arts, social studies, or even math lessons. 


\section{Finding Support Within a "Supportful" Society}

The need to incorporate diverse and multicultural curriculum in schools is not new. New curriculum and teaching strategies are continuously being introduced to meet the need of teaching children tolerance and acceptance within our society. What is new, however, is the changing mindset that people are beginning to embed into their subconscious. Simple gestures, remarks, and strategies can be incorporated almost automatically to show appreciation for one's cultural and ethnic background. Jim Cummins' (2007b) research on dual language texts demonstrated that travelling along a multicultural route does not require taking a whole new direction; rather, it is a move along a trodden path with some new little twists and turns added in. In terms of policy and practice, multicultural education can be easily implemented, as it is a set of beliefs and a philosophy that does not require a fixed set of rules or a set program (Nieto, 2006). Nieto argues that in order for educators to embrace the diversity of their students and communities, four levels that must be considered: "tolerance; acceptance; respect; and, finally, affirmation, solidarity and critique" (p. 19). Ultimately, to have a true multicultural agenda many facets must be addressed, explored, and perhaps (re)discovered.

The students in this class became researchers and presented their findings through their writing and creation of a personal cultural display. They created their own identity text, which allowed them to illustrate their self-image while gaining greater acceptance and stronger conceptions of self-identity (Cummins, 2007b). Cummins pointed out the importance of allowing students to hold a mirror up to themselves so that their identities could be reflected back in a positive light. He went on to say that "when students share identity texts with multiple audiences (peers, teachers, parents, grandparents, sister classes, the media, etc.) they are likely to receive positive feedback and affirmation of self in interaction with these audiences" (p. 235). A sharing of identity texts took place at the cultural fair, at which students presented their research to their peers, teachers, and members of their community.

Choices teachers make in the classroom have lasting effects and impressions on students. It is through these "pedagogical options that build on and extend the cultural and linguistic capital that students bring to school" that students are actively engaged (Cummins, 2006, p. 5). When the students began their research by conducting Google searches online, they engaged with technology in a way that was personally and at the time culturally significant to themselves. Through teaching tools and strategies, all students in the classroom were invited to be participants and to have agency in their social and academic choices. This could ultimately lead to promoting students' overall well-being and academic development.

\section{Acknowledgments}

The author is grateful to Professors Jim Cummins and Jim Slotta for their insightful comments on earlier drafts of this paper and to the anonymous reviewers for their feedback and helpful suggestions. 


\section{References}

Banks, J. A. (1997). Educating citizens in a multicultural society. New York, NY: Teachers College Press.

Banks, J. A. (2006). Cultural diversity and education: Foundations, curriculum, and teaching $\left(5^{\text {th }}\right.$ ed.). Boston, MA: Pearson.

Bissoondath, N. (1998). No place like home. New Internationalist, 305, 1-4.

Canadian Charter of Rights and Freedoms, Part I of the Constitution Act, 1982, being Schedule B to the Canada Act 1982 (U.K.), 1982, c. 11.

Canadian Multiculturalism Act, R.S., 1985, c. 24 (4th Supp.).

Chan, E. (2007). Student experiences of a culturally sensitive curriculum: Ethnic identity development amid conflicting stories to live by. Journal of Curriculum Studies, 39(2), 177194.

Cummins, J. (2001). Negotiating identities: Education for empowerment in a diverse society (2nd ed.). Los Angeles: California Association for Bilingual Education.

Cummins, J. (2006). Multiliteracies and equity: How do Canadian schools measure up? Education Canada, 46(2), 4-7.

Cummins, J. (2007a). Total immersion or bilingual education? Findings of international research on promoting immigrant children's achievement in the primary school. Paper presented at the 16th Annual Conference of the Commission for Teaching and Research into Primary Education of the German Association for Education, Free University of Berlin, Germany, 25 September; and at the Language, Education, and Diversity conference, University of Waikato, Aoteroa, New Zealand, 24 November.

Cummins, J. (2007b). Rethinking monolingual instructional strategies in multilingual classrooms. Canadian Journal of Applied Linguistics, 10(2), 221-240.

Darder, A. (1991). Culture and power in the classroom: A critical foundation for bicultural education. New York: Bergin \& Garvey.

Delpit, L. (1995). Other people's children: Cultural conflict in the classroom. New York: The New Press.

Dudley-Marling, C. (1997). "I'm not from Pakistan": Multicultural literature and the problem of representation. The New Advocate, 10, 123-134.

Glaser, B. G. \& Strauss, A. L. (1967). The discovery of grounded theory: Strategies for qualitative research. Chicago: Aldine.

Hill-Jackson, V., Sewell, K. L, \& Waters, C. (2007). Having our say about multicultural education. Kappa Delta Pi Record, 43(4), 174-181.

Hyun, E. (2007). Cultural complexity in early childhood: Images of contemporary young children from a critical perspective. Childhood Education, 83(5), 261-266.

Kazemipur, A., \& Halli, S. S. (2001). Immigrants and "new poverty": The case of Canada. International Migration Review, 35(4), 1129-1156.

Kendall, F. E. (1983). Diversity in the classroom: A multicultural approach to the education of young children. New York: Teachers College Press.

Kymlicka, W. (2003). Being Canadian. Government and Opposition, 38(3), 357-385.

Kymlicka, W. (2007). Ethnocultural diversity in a liberal state: Making sense of the Canadian model(s). In K. Banting, T. J. Courchene, \& L. Seidle (Eds.), The art of the state: Vol. 3. Belonging? Diversity, recognition and shared citizenship in Canada (pp. 39-86). Montreal, Quebec, Canada: Institute for Research on Public Policy.

Lee, J. W., \& Hebert, Y. M. (2006). The meaning of being Canadian: A comparison between youth of immigrant and non-immigrant origins. Canadian Journal of Education, 29(2), 497-520.

Merryfield, M. M. (2004). Elementary students in substantive culture learning. Social Education, 68(4), 270-274.

Paccione, A. V. (2000). Developing a commitment to multicultural education. Teachers College Record, 102(6), 980-1005.

Peck, C. L., Sears, A., \& Donaldson, S. (2008). Unreached and unreasonable: Curriculum standards and children's understanding of ethnic diversity in Canada. Curriculum Inquiry, 38(1), 63-92. 
Picot, G,. \& Hou, F. (2003). The rise in low-income rates among immigrants in Canada (Analytical Studies Research Paper Series 11F0019MIE2003198). Ottawa, ON: Analytical Studies Branch, Statistics Canada.

Portes, A., \& Rumbaut, R. G. (2001). Legacies: The story of the immigrant second generation. Berkeley, CA: University of California Press.

Nieto, S. (2006). Affirmation, solidarity and critique: Moving beyond tolerance in education. In E. Lee, D. Menkart \& M. Okazawa-Rey (Eds.), Beyond heroes and holidays (pp.18-29). Washington, DC: Teaching for Change.

Ramsey, P. G. (2004). Teaching and learning in a diverse world (3rd ed.). New York: Teachers College Press.

Toronto District School Board. (2000). Equity foundation statement and commitments to equity policy implementation. Retrieved from

http://www.tdsb.on.ca/wwwdocuments/programs/Equity_in_Education/docs/Equity_Foundati on_Statement.pdf

Urrieta, L., Jr., \& Quach, L. H. (2000). My language speaks of me: Transmutational identities in L12 acquisition. The High School Journal, 84(1), 26-35.

Wong, F. (1991). When learning a second language means losing the first. Early Childhood Research Quarterly, 6, 323-346.

Xu, S., Connelly, M. F., He, M. F., \& Phillion, J. (2007). Immigrant students' experience of schooling: A narrative inquiry theoretical framework. Journal of Curriculum Studies, 39(4), 399-422. 